\title{
A two-stage model of an arteriovenous fistula maturation process
}

\author{
DANIEL M. JODKO*, DAMIAN S. OBIDOWSKI, PIOTR REOROWICZ, KRZYSZTOF JÓŹWIK \\ Institute of Turbomachinery, Lodz University of Technology, Łódź, Poland.
}

\begin{abstract}
Purpose: An arteriovenous fistula has been a widely accepted vascular access for hemodialysis, however, a fistula maturation process is still not fully understood. In the short period of time, right after vein and artery shunting, the physical and biological changes take place mainly in the venous wall. A two-stage modeling method of arteriovenous fistula maturation process was proposed and presented. Methods: The first stage of the maturation was modeled with two-way coupled fluid structure interaction computer simulations. Whereas for the second, biological stage, a model was based on the change in the elasticity of the venous wall due to wall shear stress (WSS) modifications. Results: The relation between stress and radial and circumferential strain, based on Lame's theory, makes possible to introduce a mathematical model defining modulus of elasticity, averaged WSS, and venous diameter as time functions. The presented model enables one to predict changes in the monitored parameters in the arteriovenous fistula taking place in the time longer than 90 days. Conclusions: We found that probably the majority of fistulas can be assessed to be mature too early, when the adequate blood flow rate is achieved but mean WSS still remains at the non-physiological level ( $>10 \mathrm{~Pa})$.
\end{abstract}

Key words: hemodialysis, anastomosis, fluid structure interaction (FSI), wall shear stress, arteriovenous fistula AVF, AVF maturation

\section{Introduction}

The aim of this study was to present a two-stage method for modelling of the maturation process of a native arteriovenous (AVF) for hemodialysis. The AVF is an artificial shunt between patient's artery and vein and has been a preferred and widely accepted vascular access for hemodialysis [22] since 1960s, when it was firstly described by Brescia et al. [3]. However, due to frequent complications, it is still an Achilles' heel of hemodialysis, which significantly increases costs of the treatment. When the vein (usually the cephalic vein) is connected directly to the artery (usually the radial artery), the shunt starts to mature, which lasts from 4 to even 16 weeks in certain patients with vascular complications or other diseases. Some authors suggest that the period of 12 weeks at the minimum allows the AVF to be fully matured [9], but more effort should be made to find the optimal maturation time for particular patients. During this process, many changes can be observed in the circulatory system. Once the anastomosis (the place of the connection) is created, an increase in the blood flow rate is observed in the feeding artery. This phenomenon appears due to lower postoperative flow resistance of the modified vascular system, when the blood does not flow through a network of small capillaries. What is more, the heart starts to beat slightly faster, which results in an increase of the stroke volume and cardiac output. Thus, an intensive and non-physiological blood flow occurs in the feeding artery and the vein receiving the blood from the AVF. The flow rate is much higher than before the anastomosis creation. The vein is subjected to high arterial pressure and its diameter quickly extends [9], [10]. Then, biological changes begin in the venous wall which becomes thicker [10]. This thickening allows the nurses for frequent cannulation (2-3 times a week) with large needles for hemodialysis. Remodelling of the artery is

\footnotetext{
* Corresponding author: Daniel Jodko, Institute of Turbomachinery, Lodz University of Technology, ul. Wólczańska 219/223, 90-924 Łódź, Poland. Phone: +48 500778018, e-mail: daniel.jodko@p.lodz.pl

Received: February 19th, 2020

Accepted for publication: April 21st, 2020
} 
not observed in the first 12 weeks, however, this blood vessel is dilated after one year since the anastomosis creation [9]. This phenomenon is related to a slow change in the heart operation, which is a response to a new environment of the low-resistance flow in the AVF.

AVF maturation is a complex process in which several hemodynamic factors play a key role resulting in biological response. Maturation begins when the vein is sewed to the artery and clamps are released to allow the blood inflow into the venous arm of the created AVF. The process is associated with patientindividual features, blood vessel conditions, other illnesses, etc. One of the most important factors influencing maturation success is the minimal preoperative vein diameter, which should be equal to $2.5 \mathrm{~mm}$ [15]. However, the diameter equal to $3 \mathrm{~mm}$ significantly increases a possibility of successful maturation.

The AVF should be regularly monitored by measurements of the flow rate of blood incoming through the artery. Accordingly to Konner et al. [15], the minimal value of the blood volume flow rate should be around $5.83-6.67 \mathrm{~cm}^{3} / \mathrm{s}(350-400 \mathrm{ml} / \mathrm{min})$, values lower than $5.00 \mathrm{~cm}^{3} / \mathrm{s}(300 \mathrm{ml} / \mathrm{min})$ can result in recirculation, whereas values lower than $3.33 \mathrm{~cm}^{3} / \mathrm{s}$ $(200 \mathrm{ml} / \mathrm{min})$ are associated with a high risk of clot formation [15]. Depending on the country, AVF type and research, even $20-50 \%$ of AVFs fail to mature [10] due to typical complications, e.g., stenoses, aneurysms, thrombosis, etc. The reasons can be related to extreme values of the wall shear stress (WSS) generated by the non-physiological blood flow in the vein. High WSS influences the endothelial cells in the inner layer of the blood vessel, which can lead to intimal hyperplasia and narrowing formation. Low WSS, associated with low blood velocity, may cause thrombus formation. What is more, there is a hypothesis saying that WSS, which rapidly grows with a sudden increase in the flow rate after anastomosis creation, should decrease to a normal venous value during the maturation [15]. Typical physiological values of WSS for veins and arteries are estimated by various authors to be at the level of $0.1-1 \mathrm{~Pa}$ and 1-7 $\mathrm{Pa}$, respectively [6], [7]. Accordingly to the hypothesis described by Konner et al. [15], the increase in the venous diameter lasts until WSS achieves a physiological venous level. It was experimentally proven by Corpataux et al. [9], who found that WSS returns to baseline values (average fall from $2.45 \mathrm{~Pa}$ to $1.04 \mathrm{~Pa}$ ) after 12 weeks in 6 patients. In the same study, the authors monitored a rise of the averaged radial inflow from $8.98 \mathrm{~cm}^{3} / \mathrm{s}$ ( $539 \mathrm{ml} / \mathrm{min})$ up to $12.50 \mathrm{~cm}^{3} / \mathrm{s}(750 \mathrm{ml} / \mathrm{min})$ between the 1st and 12th week. Therefore, to decrease WSS, which grows with an increase in the flow rate, the vein has to enlarge its internal diameter. This is a hypertrophic process associated with the induced proliferation, which results in the growth of cells and the tissue mass enlargement. Between the 1st and 12th week of maturation any significant changes in the blood pressure in the venous arm of the AVF are not observed [9].

It should be emphasized here that WSS cannot be directly measured in complex geometries with experimental methods. It can be only estimated with precise measurements of velocity fields close to the wall of the channel (which is extremely difficult in geometrically varying channels) or it can be precisely calculated with computational fluid dynamics (CFD). Modelling of the AVF maturation process is discussed in a few papers [18], [19], however, other authors do not distinguish any steps in their models. Therefore, this paper proposes a new two-stage method of modelling of the vein dilation during maturation based on the estimation of WSS and venous adaptation.

\section{Materials and methods}

Selected mechanical factors, which rapidly change blood flow conditions after anastomosis creation, were taken into account in this study: increase in the blood pressure in the vein, large raise in the blood flow rate in the vein after bypassing capillary network in hand, increase of the blood flow in the feeding artery due to a change of high-resistive flow into lowresistive typical for veins, increase in the instantaneous and time-averaged WSS in the artery and vein, related to increase of blood velocity.

Due to duration of the changes and domination of particular factors, two stages of maturation placed in two different time scales were distinguished: 1) mechanical initial stage - lasting maximally a few minutes since the anastomosis creation and associated with mechanical extension of the vein, 2) biological remodelling stage - lasting even 16 weeks since the end of the initial stage until the moment, in which the area-averaged WSS achieves the typical venous level.

Timescales of both stages are much longer than one cardiac cycle equal to $0.83 \mathrm{~s}$ (for $72 \mathrm{bpm}$ ). What is more, Corpataux et al. in the experimental study did not observe significant changes in the diameter of the radial artery $(0.056 \mathrm{~mm}, 1.5 \%$ of the mean diameter $)$ and cephalic vein $(0.09 \mathrm{~mm}, 2.2 \%$ of the mean diameter), caused by blood pulsations [9]. Thus, pulsations of the blood flow were neglected in simulations of 
both stages and changes in time-averaged conditions were taken into account. Therefore, oscillatory shear index was not investigated in this study.

Initial stage of maturation is related to mechanical extension of the vein caused by the arterial highpressure blood, which is abnormal for vein. The vein, built of tissue which is much less resistant than arterial wall, is quickly and significantly expanded. The arterial blood freely finds an estuary into low-resistance environment of the vein. This results in the growth of the blood flow rate in the cephalic vein. In case of radiocephalic AVF this is even 72-fold increase on average from $0.083 \mathrm{~cm}^{3} / \mathrm{s}(5 \mathrm{ml} / \mathrm{min})$ preoperatively up to $6 \mathrm{~cm}^{3} / \mathrm{s}(360 \mathrm{ml} / \mathrm{min})$ after anastomosis creation [10]. Moreover, the change in the flow conditions is associated with alteration of heart operation, which results in rise of the blood inflow in the radial artery. According to Dixon [10], the radial blood flow is increased 11 times during one day after AVF creation, however Caroli et al. [5] observed even 17-fold rise of the flow during one day after the surgery. Such increase of the flow rate causes growth in blood velocity, which increases WSS generated by the blood on arterial and venous endothelium.

The second stage of the maturation begins when the first step is finished and hemodynamic conditions in the receiving vein are stabilized. Due to its timescale, it is convenient to assume that it is initiated since the end of the initial stage. Then, the vein is already expanded, the blood flow rate is significantly enlarged, and arterial pulsations are observed in the vein. Therefore, averaged WSS is greatly increased, and under such new conditions, the long process of remodelling starts. Morphology and structure of the venous arm of the AVF start to change and slow dilation of the vein begins.

\subsection{Modelling of the first mechanical stage of maturation}

The first stage of maturation was modelled with a two-way coupled fluid structure interaction (FSI) technique available in ANSYS $^{\circledR}$ R15.0 package. The software provides a possibility of conducting transient analyses through solving of Reynolds-Averaged Navier -Stokes equations representing the unsteady flow phenomena in the fluid domain and equations describing behaviour of the elastic structure of channels. At the timestep $t=0 \mathrm{~s}$, the vein was considered to be a circular tube filled by the blood, with venous initial di- ameter equal to $3 \mathrm{~mm}$ and its thickness constant along the vessel and equal to $0.5 \mathrm{~mm}$. On the basis of the geometrical data of mature AVFs, models of the immature ones were built (Fig. 1) using the method of model development described in details in [26]. Due to the fact that the wall condition was assumed on the clamped accessory veins (black Xs in Fig. 1), the simplified geometrical models had one arterial inlet and one venous outlet.

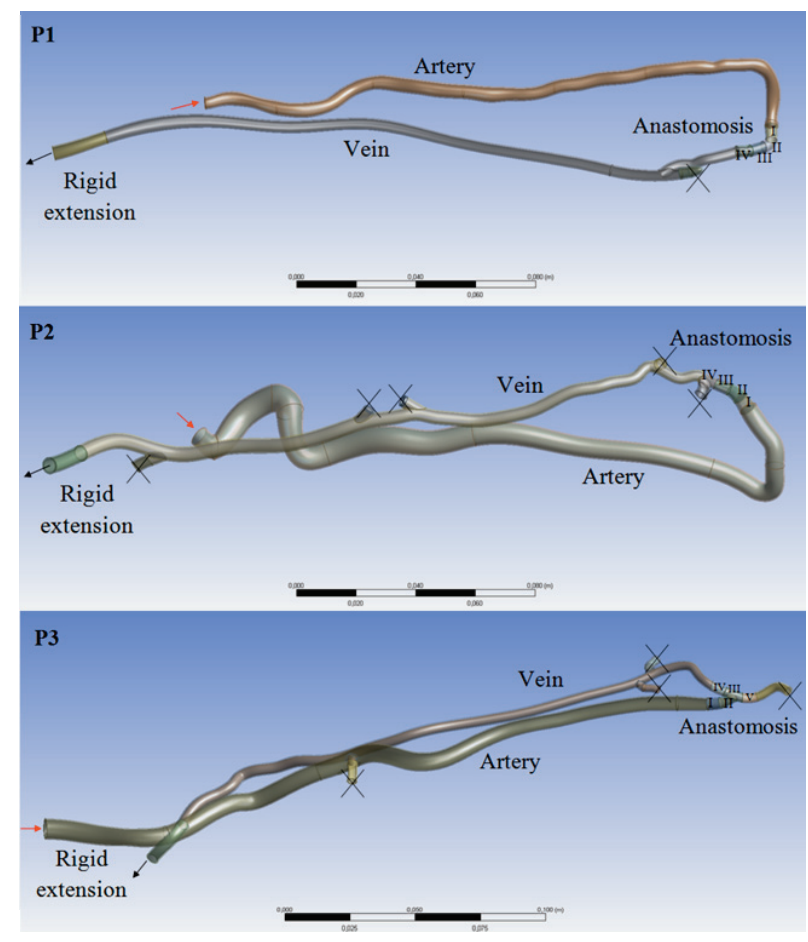

Fig. 1. Immature AVF models used in FSI modelling; red arrow - inlet, black arrow - outlet, cross - clamped blood vessel

For each case, the artery, short parts of the accessory veins and the end of the cephalic vein were assumed to be rigid. Annular cross-sections of the inlet, outlet and ends of the small veins were considered to be motionless due to the fact that the AVF is stabilized by the surrounding tissues which were not modelled here. However, no force was applied to external walls of the shunts, since AVF is always placed just under the skin. Cephalic veins as well as anastomotic parts III and IV, which were a beginning of the vein before anastomosis creation, were treated as elastic.

The venous wall was assumed to be composed of isotropic and homogenous material. For all cases, the Poisson's ratio of the material was assumed to be equal to 0.45 . Values of the ratio determined by other researchers are in the range 0.33-0.5 [16], [28]. Analysis of the literature allows one to state that extension of the cephalic vein at the beginning of maturation is not larger than $100 \%$ of the initial diameter [5], [9], [10]. 
Despite the fact that blood vessels are hyperelastic composites and due to lack of an appropriate widely accepted mathematical model describing the venous behaviour, it was considered to be linear. In each case, the tests were performed to determine a value of Young's modulus. The outcome obtained from the test was a set of different geometries for each AVF model (P1 to P3). From the set one, resultant geometry, most similar in average diameter to the expected one for the first stage of AVF maturation, enabled one to determine elastic modulus for each case. The values of elastic modulus used in this study (Table 1) are close to Young's modulus determined for human saphenous vein in similar range of pressure [28].

In the present study, it was important to gain quantitative results of wall displacement. Since the stress in the wall was not considered, it was possible to use tetrahedral meshes with lower refinement (solid 187). To shorten the calculation time, the arteries could be removed, however, it is important to take these vessels into consideration due to forming of the blood velocity profile and other flow phenomena upstream of the anastomoses. Neglecting of the arteries could change the flow structure and, as a consequence, the blood reaction on the venous wall, thus it was decided to include them in the analysis.
Fine and dense grids were build in fluid domains to represent the volume of flowing blood in FSI simulations. Meshes containing 1.20, 2.21, and 2.37 million finite volumes were generated for P1, P2, and $\mathrm{P} 3$, respectively. Grids in the fluid domains were tested according to the grid convergence index (GCI) method, which was successfully used for modelling of blood flows in other cases [4], [13]. A total time of the first stage, associated with rapid increase of the blood flow rate and venous pressure, was assumed to be equal to $30 \mathrm{~s}$. At arterial inlets a time-dependent flow rate was assumed, that increases in first $25 \mathrm{~s}$ and becomes constant for the next $5 \mathrm{~s}$ of each simulation (Fig. 2).

The increase in the flow rate was estimated on the basis of average experimental data obtained in large group of patients by Caroli et al. [5]. Thus, a linear increase of the flow rate from $0.35 \mathrm{~cm}^{3} / \mathrm{s}(21 \mathrm{ml} / \mathrm{min})$ up to $5.92 \mathrm{~cm}^{3} / \mathrm{s}(355 \mathrm{ml} / \mathrm{min})$ for end-to-end AVFs (P1, P2) and from $0.28 \mathrm{~cm}^{3} / \mathrm{s}(17 \mathrm{ml} / \mathrm{min})$ up to 3.28 $\mathrm{cm}^{3} / \mathrm{s}(197 \mathrm{ml} / \mathrm{min})$ for the end-to-side AVF (P3) was assumed. During the assumed time of $30 \mathrm{~s}$, approximately 30-40 heart beats would be normally observed. Modelling of these pulsations would be associated with necessity of decreasing of the timestep and would need to use of much larger computational

Table 1. Mesh and material parameters used in the structural modelling

\begin{tabular}{|c|c|c|c|c|c|c|c|}
\hline \multirow[b]{2}{*}{ Case } & \multicolumn{3}{|c|}{ Mesh } & \multicolumn{3}{|c|}{ Material } & \multirow{2}{*}{$\begin{array}{c}\text { Initial } \\
\text { thickness } \\
{[\mathrm{mm}]}\end{array}$} \\
\hline & $\begin{array}{l}\text { Number } \\
\text { of nodes }\end{array}$ & $\begin{array}{c}\text { Number } \\
\text { of finite elements }\end{array}$ & $\begin{array}{l}\text { Skewness } \\
\text { - average }\end{array}$ & $\begin{array}{c}\text { Young's } \\
\text { modulus [MPa] }\end{array}$ & $\begin{array}{c}\text { Poisson's } \\
\text { ratio [-] }\end{array}$ & $\begin{array}{l}\text { Density } \\
{\left[\mathrm{kg} / \mathrm{m}^{3}\right]}\end{array}$ & \\
\hline $\mathrm{P} 1$ & 301939 & 162242 & 0.30 & 0.40 & \multirow{3}{*}{0.45} & \multirow{3}{*}{1060} & \multirow{3}{*}{0.5} \\
\hline $\mathrm{P} 2$ & 706570 & 394769 & 0.31 & 0.55 & & & \\
\hline P3 & 625203 & 344234 & 0.33 & 0.35 & & & \\
\hline
\end{tabular}

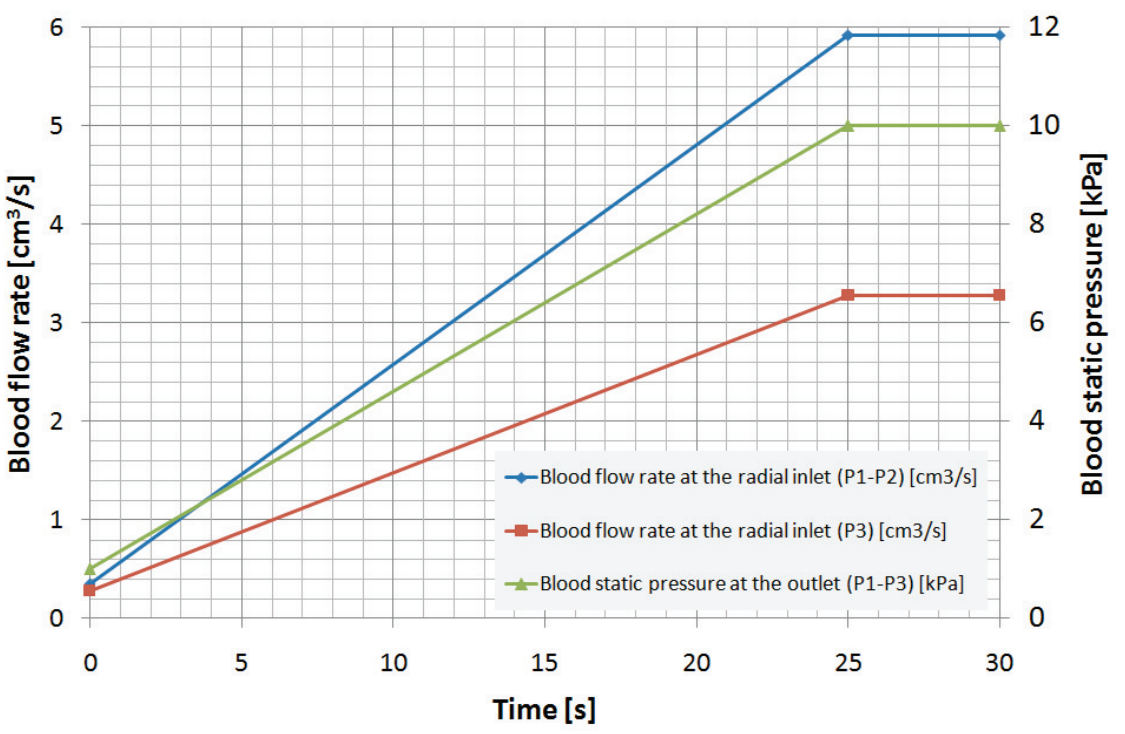

Fig. 2. Boundary conditions used in FSI modelling 
power, therefore, they were neglected. The performed simulations were conducted with averaged parameters. This approach is consistent with the findings presented in [13]. On the outlets of all investigated AVFs, the growth of blood static pressure from $1 \mathrm{kPa}$ $(7.5 \mathrm{mmHg})$, which is a normal venous pressure [23], up to $10 \mathrm{kPa}(75.0 \mathrm{mmHg})$ in $25 \mathrm{~s}$ of simulation was assumed. In the last $5 \mathrm{~s}$, the pressure becomes constant.

Time of 30 seconds is an assumed value, since there was no information found in the literature related to in vivo investigations of the mechanical extension of the AVF venous arm. We only know, that the process is "sudden" [15]. The assumption of $30 \mathrm{sec}-$ onds of total simulation time with use of timestep equal to $0.1 \mathrm{~s}$ and available computer made it possible to conduct particular simulations in real time of few days. This is a compromise between precision of calculations and their costs. Due to changing flow conditions and possibility of occurrence of low and high velocity gradients, the non-Newtonian model based on Power Law was applied similarly to [26]. Body of the hemodialyzed patient accumulates large amount of water. Thus, the density of the blood was assumed to be equal to $1040 \mathrm{~kg} / \mathrm{m}^{3}$, which is a value a bit lower than for typical arterial blood. A commercial code provided by $\mathrm{ANSYS}^{\circledR} 15.0$ was used for solving equations of continuity, momentum and energy conservation. Two equation Shear Stress Transport (SST) model of turbulence was used, since it combines advantages of $k-\omega$ and $k-\varepsilon$ models and is appropriate for complicated channels and relatively low Reynolds number [20] and it proves its robustness in blood flow modelling [13], [26]. One personal workstation was used for all calculations: Intel Core i7-3930K $3.20 \mathrm{GHz}$, 4 cores, 64.0 GB RAM.

\subsection{Modelling of the second biological stage of maturation}

The first stage of maturation ends with stabilization of hemodynamic conditions in the average time scale, probably maximally within few minutes. This is the beginning of much longer biological stage of the maturation process, which is associated with relaxation of WSS in the vein as well as in the artery. However, as mentioned before, the remodelling of the artery is a long-term process and it is neglected here. What is more, in vivo measurements done by Corpataux et al. [9] and by Sigovan et al. [27] showed that there is no significant change in arterial diameter be- tween 1 and 12 week after anastomosis creation. Similarly, the radial artery did not dilate substantially between 10 and 100 days in observations of 28 patients described in [11] and between 20 and 100 days in modelling of maturation introduced by Manini et al. [19]. Thus, remodelling of this vessel was not taken into account here, nevertheless, this assumption was compensated by the use of the arterial inflow specific for particular stages of AVF maturation. Remodelling of the venous arm of the AVF is much faster and much more important from the point of view of hemodialysis therapy.

The simulation of the biological stage was performed with an introduced material model describing time-dependent mechanical properties of the maturing venous wall. Obviously, this structural change is a desirable phenomenon because the wall becomes strengthened, which enables the nurses to insert relatively thick needles for hemodialysis. The proposed way of modelling is based on the mentioned hypothesis connecting the vein adaptation to new flow conditions and decreasing of WSS during AVF maturation.

The proposed material model assumes relation between elastic modulus of venous tissue (material parameter $E^{\prime}$ ) and WSS (flow parameter) or the second power of WSS

$$
\begin{aligned}
& E^{\prime}=\frac{A}{\mathrm{WSS}}, \\
& E^{\prime}=\frac{B}{\mathrm{WSS}^{2}},
\end{aligned}
$$

where $A\left[\mathrm{~Pa}^{2}\right]$ and $B\left[\mathrm{~Pa}^{3}\right]$ are introduced constants, and WSS can be estimated from

$$
\mathrm{WSS}=\frac{4 \eta Q}{\pi R^{3}}
$$

where $\eta[\mathrm{Pa} \mathrm{s}]$ is the blood dynamic viscosity, $Q\left[\mathrm{~m}^{3} / \mathrm{s}\right]$ is the blood flow rate, and $R[\mathrm{~m}]$ is the internal radius of the vein.

As WSS is directly proportional to the flow rate, it is inversely proportional to the third power of the radius, thus, shear stress falls rapidly when the vein is extended. According to equations (1) and (2), decreasing of WSS is connected to rising of the elastic modulus and stiffening of the vein, which is normally observed during maturation. What is more, the assumption allows one to model hyperelastic behaviour of the tissue for large deformation since the relation WSS-R is not linear.

It was assumed that during the biological stage, the arterial inflow rises slowly for three months after AVF creation. The increase in the flow rate was based on 

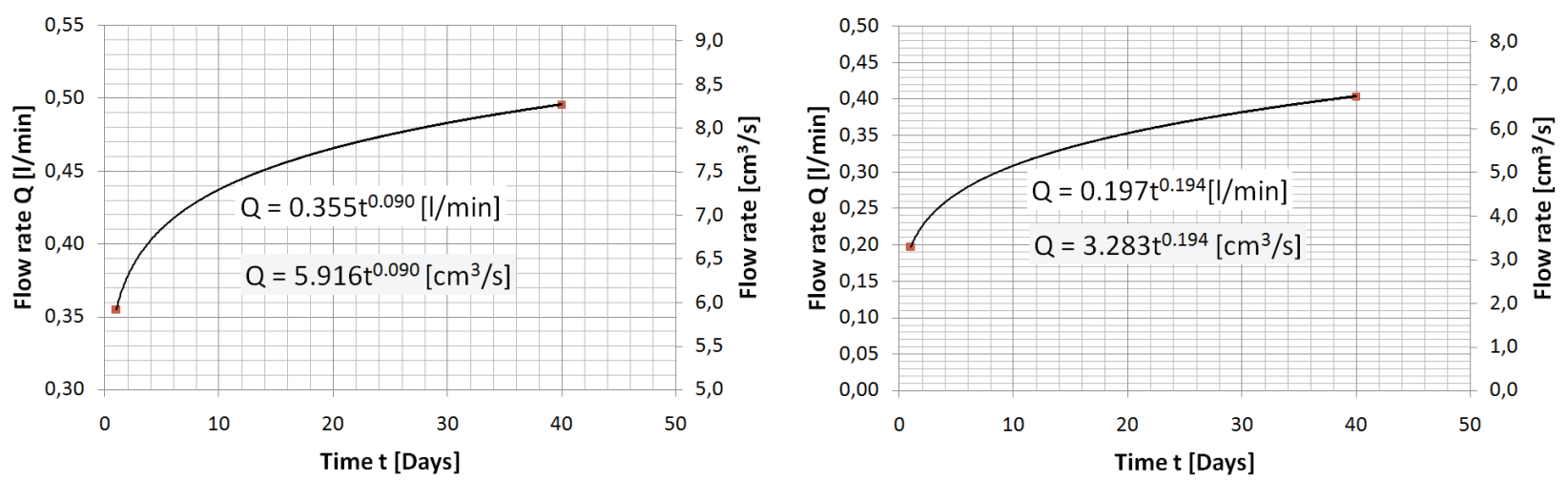

Fig. 3. Flow rate power functions based on experimental data published by Caroli et al. [5] used in simulations of the biological stage of maturation for end-to-end (left) and end-to-side (right) shunts

averaged rising flow rate determined experimentally in large group of patients by Caroli et al. [5] during 40 days from AVF creation separately for end-to-end (P1-P2) and end-to-side (P3) AVFs. For the need of this study, the changes of the flow rate in time were described by power functions, which allows one to predict values of the flow rate in time longer than 40 days (Fig. 3). That is important because 3 months of maturation are taken into account in the present study.

To model the biological stage of maturation, expressions derived in XIX century by French mathematician and engineer Gabriel Lamé were used. The formulas are appropriate for a thick pipe, whose wall thickness is bigger than $10 \%$ of its internal radius $(g>0.1 R)$. The constant value of external pressure $\left(p_{b}=0 \mathrm{kPa}\right)$ and blood pressure $\left(p_{a}=10 \mathrm{kPa}\right)$ equal to the final pressure obtained in the end of the mechanical stage was assumed during the whole biological stage (Fig. 4).
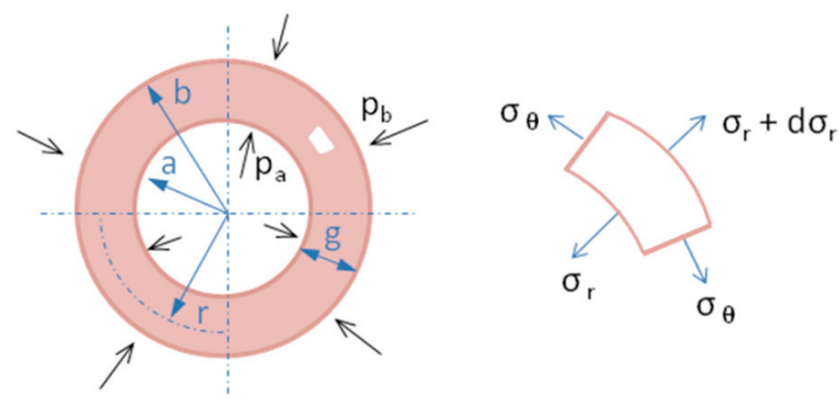

Fig. 4. The load applied to the thick Lamé pipe and state of stress in its small region

This assumption is corresponding to in vivo longterm observations done in human AVFs by Corpataux et al. [9]. Initial thickness $(g)$ was equal to the final thickness of the venous wall obtained in the first stage of the modelling in a not supported part of the vein indicated in Fig. 5. The thickness was assumed to be constant during 90 days, which is relevant to the fact that venous tissue grows while its diameter extends, thus the process is hypertrophic. The derived equations made it possible to write an algorithm allowing one to calculate modulus of elasticity, averaged WSS, and venous diameter versus time.

For any radius $(r)$, which is in the range of $\{a, b\}$, the radial stress $\left(\sigma_{r}\right)$ and circumferential stress $\left(\sigma_{\theta}\right)$ are defined as

$$
\begin{gathered}
\sigma_{r}=\frac{p_{b} b^{2}-p_{a} a^{2}}{a^{2}-b^{2}}-\frac{p_{b}-p_{a}}{a^{2}-b^{2}} \frac{a^{2} b^{2}}{r^{2}}, \\
\sigma_{\theta}=\frac{p_{b} b^{2}-p_{a} a^{2}}{a^{2}-b^{2}}+\frac{p_{b}-p_{a}}{a^{2}-b^{2}} \frac{a^{2} b^{2}}{r^{2}} .
\end{gathered}
$$

With replacing the Young modulus in the Hooke's law by modulus of elasticity $\left(E^{\prime}\right)$, the relation between the stress and the radial and circumferential strain can be noted as

$$
\begin{gathered}
\sigma_{r}=\left(\frac{E^{\prime}}{1-v^{2}}\right)\left(\varepsilon_{r}+v \varepsilon_{\theta}\right), \\
\sigma_{\theta}=\left(\frac{E^{\prime}}{1-v^{2}}\right)\left(\varepsilon_{\theta}+v \varepsilon_{r}\right),
\end{gathered}
$$

where $v=0.45$ is a Poisson ratio.

The AVF should be placed just under the skin. Therefore, for an assumption that for $r=b$ the external pressure $p_{b}$ is close to zero and the radial extension of the inner radius $(\Delta a)$ under the internal pressure $p_{a}$ is given by

$$
\Delta a=a \varepsilon_{r}=\frac{p_{a} a}{E^{\prime}\left(b^{2}-a^{2}\right)}\left[a^{2}(1-v)+b^{2}(1+v)\right] .
$$




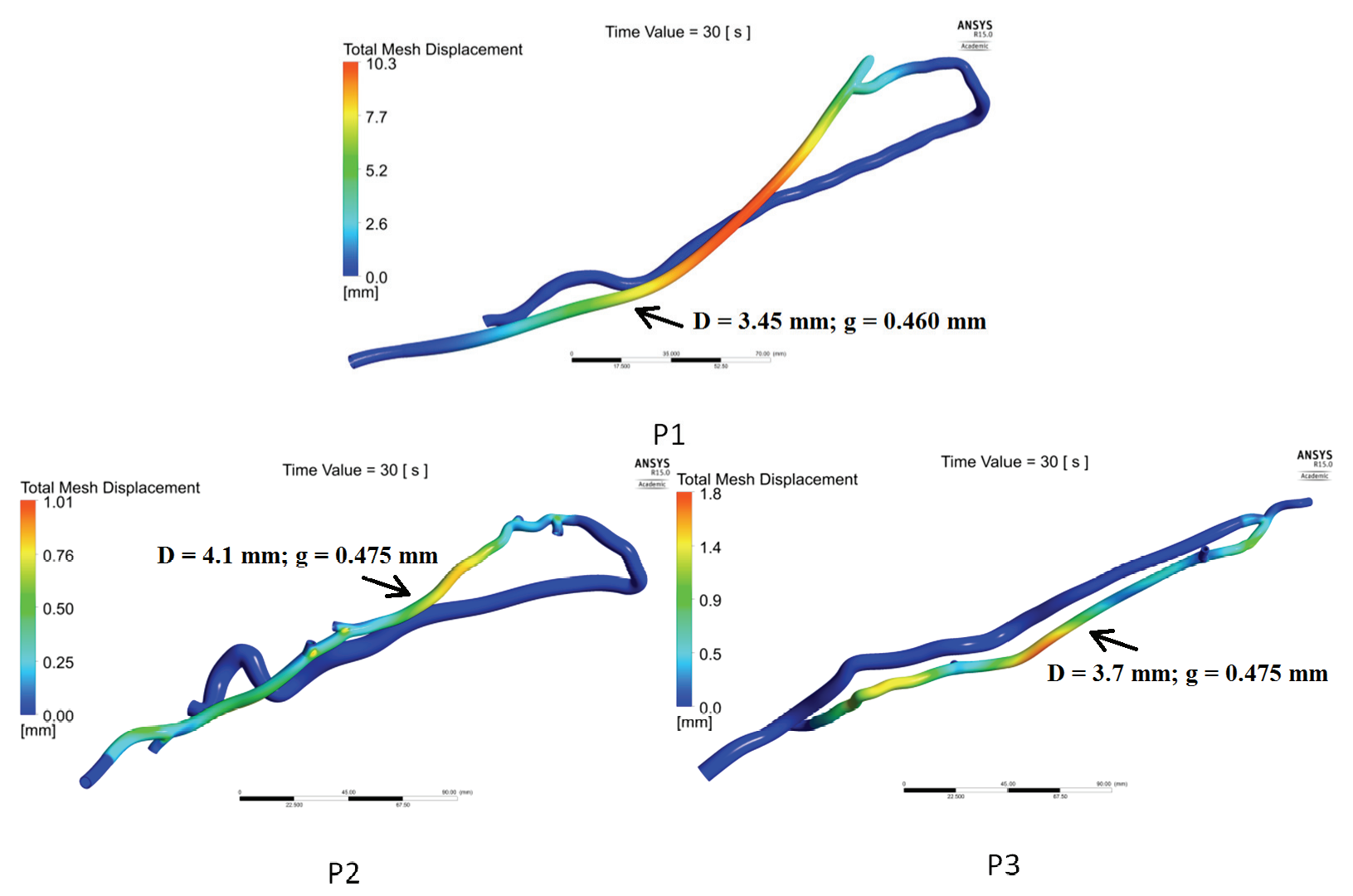

Fig. 5. Mesh displacement in space for last timestep $(t=30 \mathrm{~s})$, notice the different maximal value on the scale in particular cases; final diameter $(D)$ and wall thickness $(g)$ were indicated by black arrows

\section{Results}

Combination of the use of the commercial code provided by ANSYS $^{\circledR}$ and the self-written computer program enabled us to model the venous dilation which begins when the blood starts to flow into the AVF just after anastomosis creation.

\subsection{Mechanical stage}

The use of FSI techniques made it possible to simulate the extension of the venous arm in 3-dimensional models P1-P3. The obtained results concern the vein dilation, total mesh displacement, distribution of blood pressure and WSS on the internal walls of blood vessels, and blood flow patterns. In Figure 5, displacement of numerical grids representing the blood vessel walls in the end of simulation is shown. The highest value of the mesh displacement was found for patient P1, because of lack of accessory veins which would stabilize the cephalic vein in space. The change of the position of the free and unsupported venous wall is associated with acting of the hydrodynamic force coming from quickly changing blood velocity vectors in geometrically complicated channels. Despite position changes of the walls, an increase in diameter was similar in all cases. The motion of meshes in time for particular models is animated and shown in Supplementary materials $(\mathrm{S} 1 \mathrm{a}-\mathrm{c})$. Small instabilities of the vein, due to lack of the support along the blood vessel, can be observed in the beginning of the blood inflow for P1.

In Figure 5, the final diameter and vein thickness measured in the indicated place for particular cases are shown. These cross-sections are located in the middle part of the forearm in the certain distance from branches supporting and fixing the vessel, therefore, the results can be representative values considered as averaged longitudinally. The animations presenting the extension of the vein cross-sections (indicated in Fig. 5) are included in Supplementary materials $(\mathrm{S} 2 \mathrm{a}-\mathrm{c})$.

In Figure 6, changes in the area-averaged wall shear (AAWSS) in particular segments (Fig. 1) of investigated AVF models during the first $30 \mathrm{~s}$ of maturation of the mechanical stage are depicted. The increase of average WSS is directly connected to the rise of the 

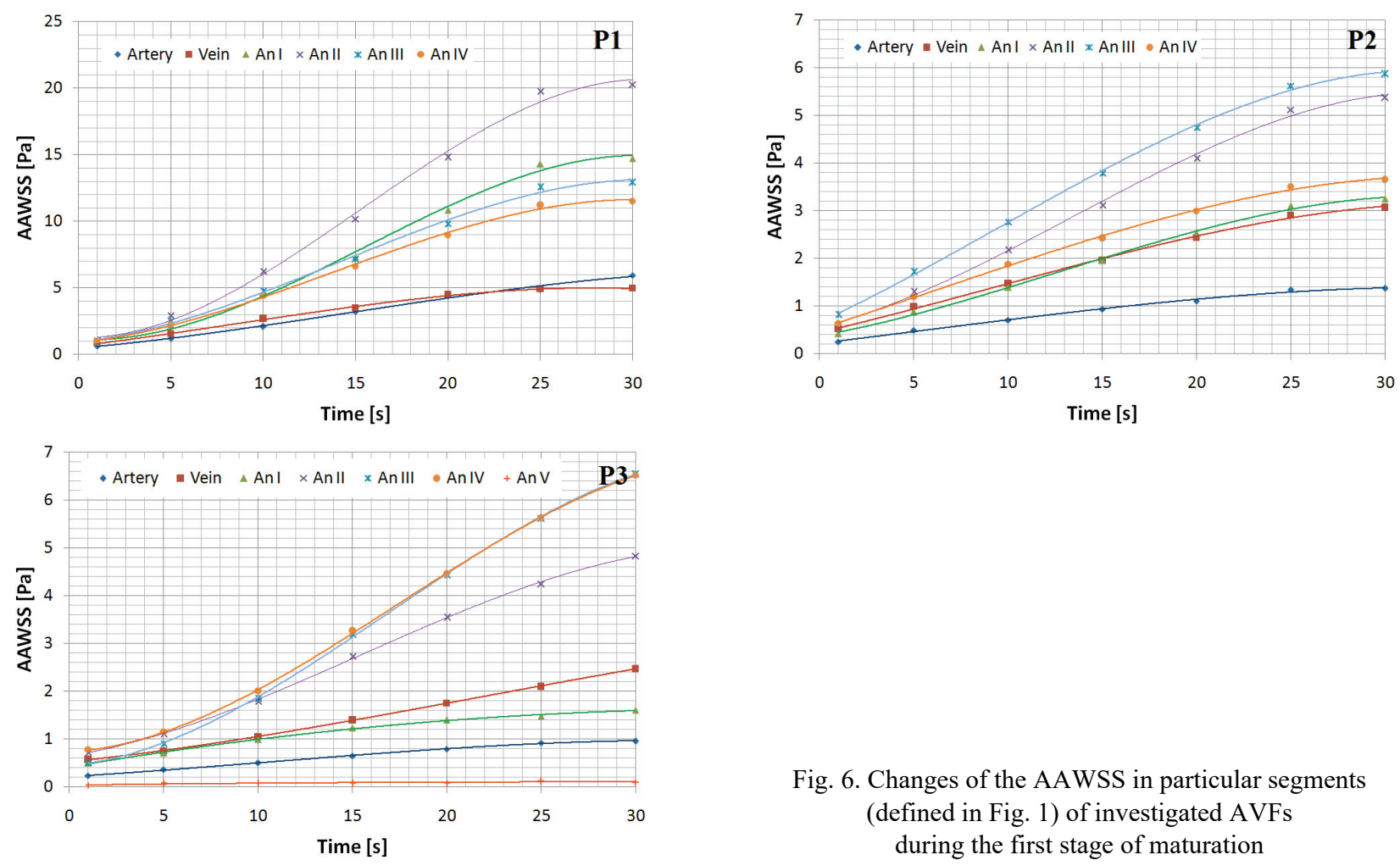

Fig. 6. Changes of the AAWSS in particular segments (defined in Fig. 1) of investigated AVFs during the first stage of maturation
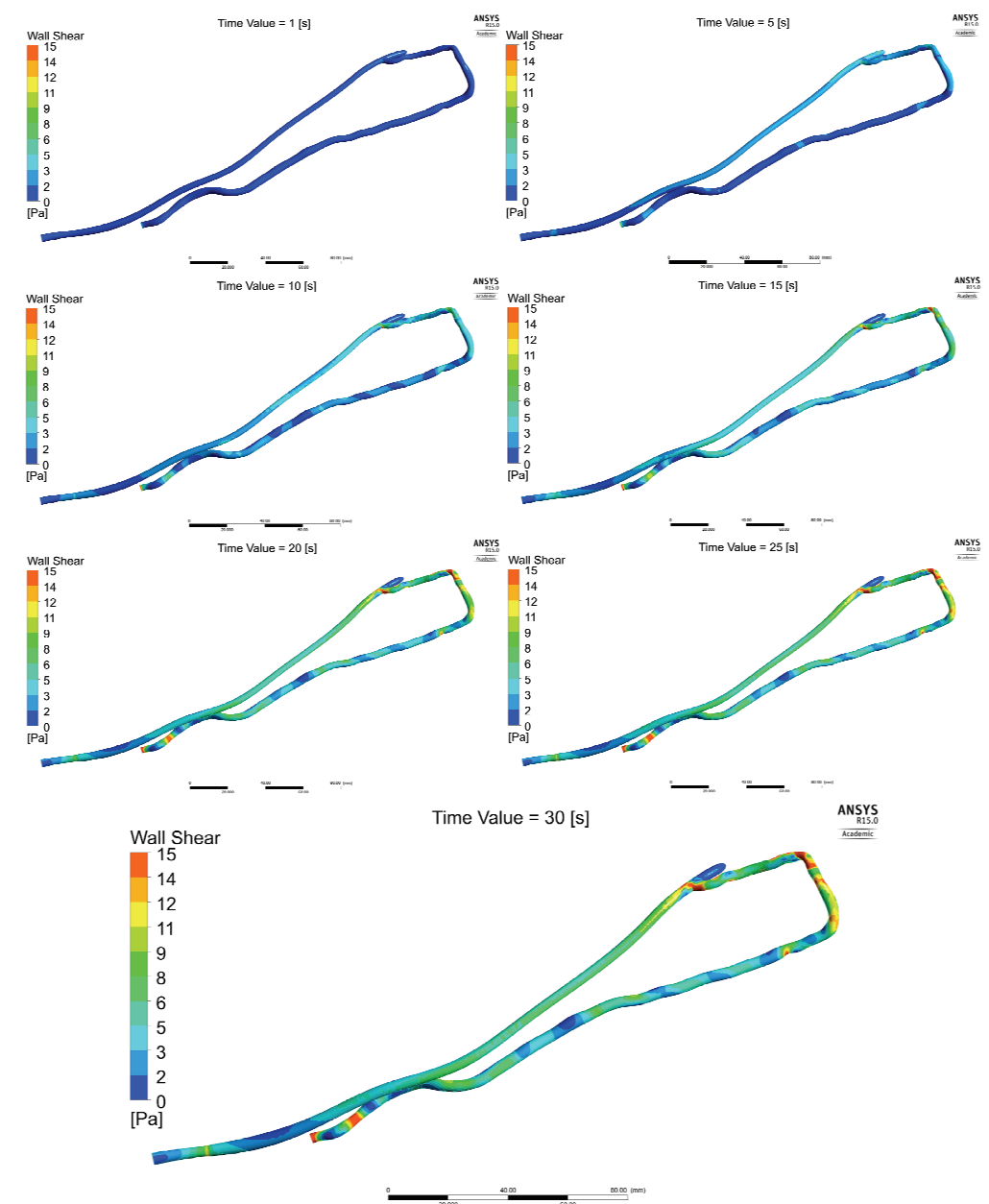

Fig. 7. Distribution of WSS in selected timesteps of the mechanical stage of maturation of the AVF P1; red colour codes WSS equal to $15 \mathrm{~Pa}$ or higher (see also an animation S3a included in Supplementary materials) 


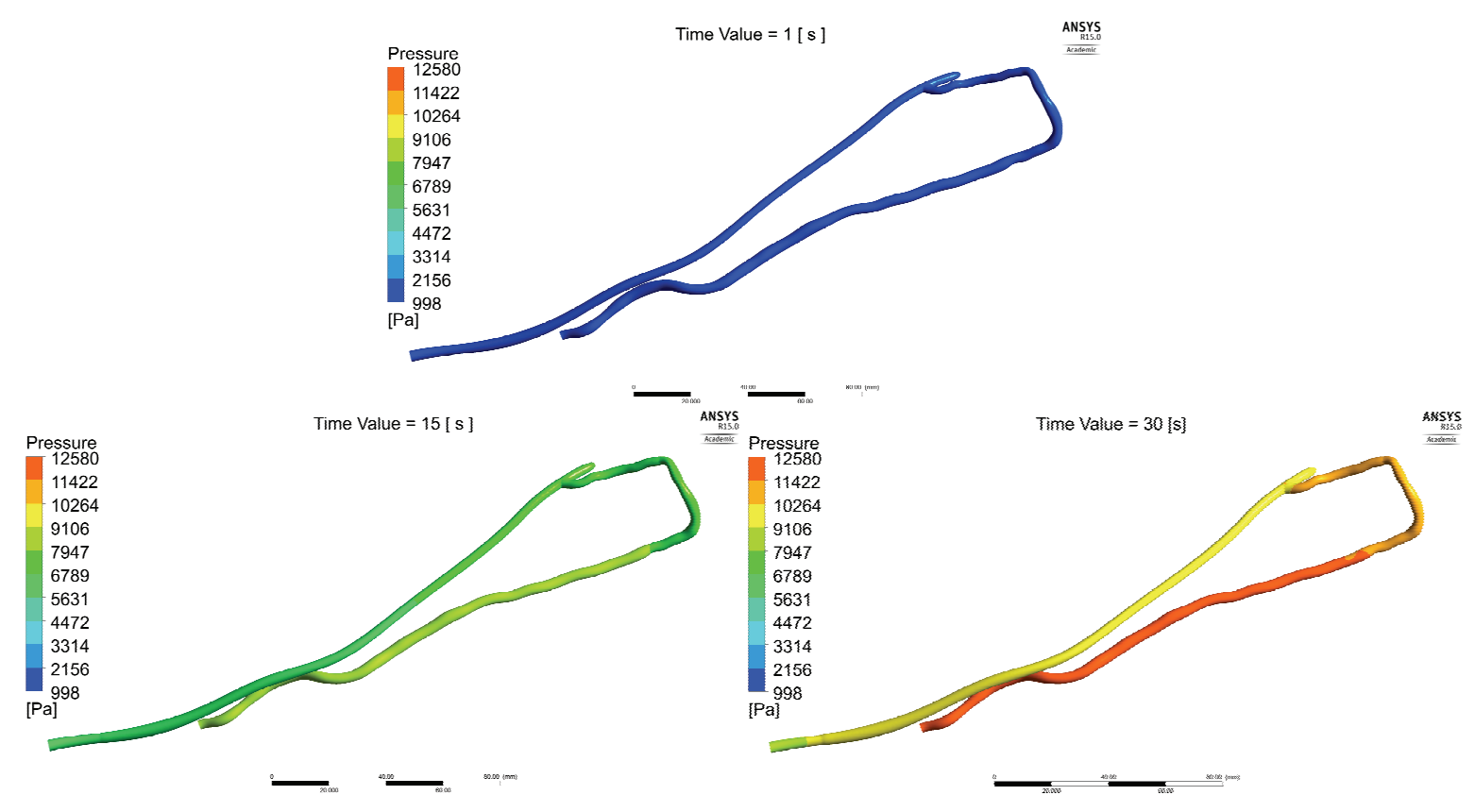

Fig. 8. Changes in the blood static pressure distribution in three selected timesteps in the AVF P1 during the mechanical stage of maturation

flow rate and associated with growth of blood velocity near blood vessel walls. The example, showing how WSS distribution changes on the inner wall of the AVF $\mathrm{P} 1$, is depicted in Fig. 7. More details and data regarding models P2 and P3 are available in Supplementary materials $(\mathrm{S} 3 \mathrm{a}-\mathrm{c})$ on animations showing how WSS changes in time. Extremely high WSS can induce intimal hyperplasia, inwards remodelling and stenosis development, which is a typical AVF complication.

Figure 8 shows changes in the blood static pressure, which increases during the mechanical stage of maturation. Animations presenting the pressure distribution during the $30 \mathrm{~s}$ of the mechanical stage in all cases are shown in Supplementary materials S4a-c.

The increasing inflow in the first stage of maturation results in rapid changes of flow structure, especially in the anastomosis zone, in which the blood velocity achieves highest values for $t=30 \mathrm{~s}$. In the last seconds of the first maturation stage, the vein is significantly enlarged close to the anastomosis, therefore, vortices are induced in juxta-anastomotic vein. In the centre of vortex the blood velocity is low, which results in high values of velocity gradients (shear strain rate) and vorticity [1], [21]. Thus, even in this stage of maturation, new hemodynamics can induce hemolysis and thrombus activation. What is more, these phenomena are enhanced by pulsating character of the arterial blood inflow and can lead to early thrombosis. The images showing the development of velocity fields and blood flow patterns during the modelled mechanical stage of maturation are presented in Supplementary materials (S5).

\subsection{Biological stage}

Changes in parameters, monitored during the biological stage of maturation lasting 90 days, are presented in Figs. 9-11. In these figures, one can notice blue and green points representing two ways of modelling considering the relation between elastic modulus and WSS or $\mathrm{WSS}^{2}$, respectively. Initial points, corresponding to the AAWSS obtained in the venous arm of each AVF in the end of the first stage of maturation (Fig. 6), are marked in the charts for $t=0$. The graphs present increase in the elastic modulus with simultaneous lowering of the estimated WSS, representing the average WSS in the venous arm of each investigated AVF. Constants A and $\mathrm{B}$ used to obtain the presented curves are given in captions.

In Table 2, the comparison of diameters obtained with the proposed method to experimental data found in the literature is shown. Modelling performed for 365 days results in further changes in the venous diameter and WSS, however, the curve course representing the relation between the modulus of elasticity and $\mathrm{WSS}^{2}$ changes to asymptotical much faster than the second one. Thus, the method with use of $\mathrm{WSS}^{2}$ as a determinant factor allows one to obtain more likely results (underlined values in Table 2) and seems to be a better approach, since the other one gives improbably large values of diameter after one year. 

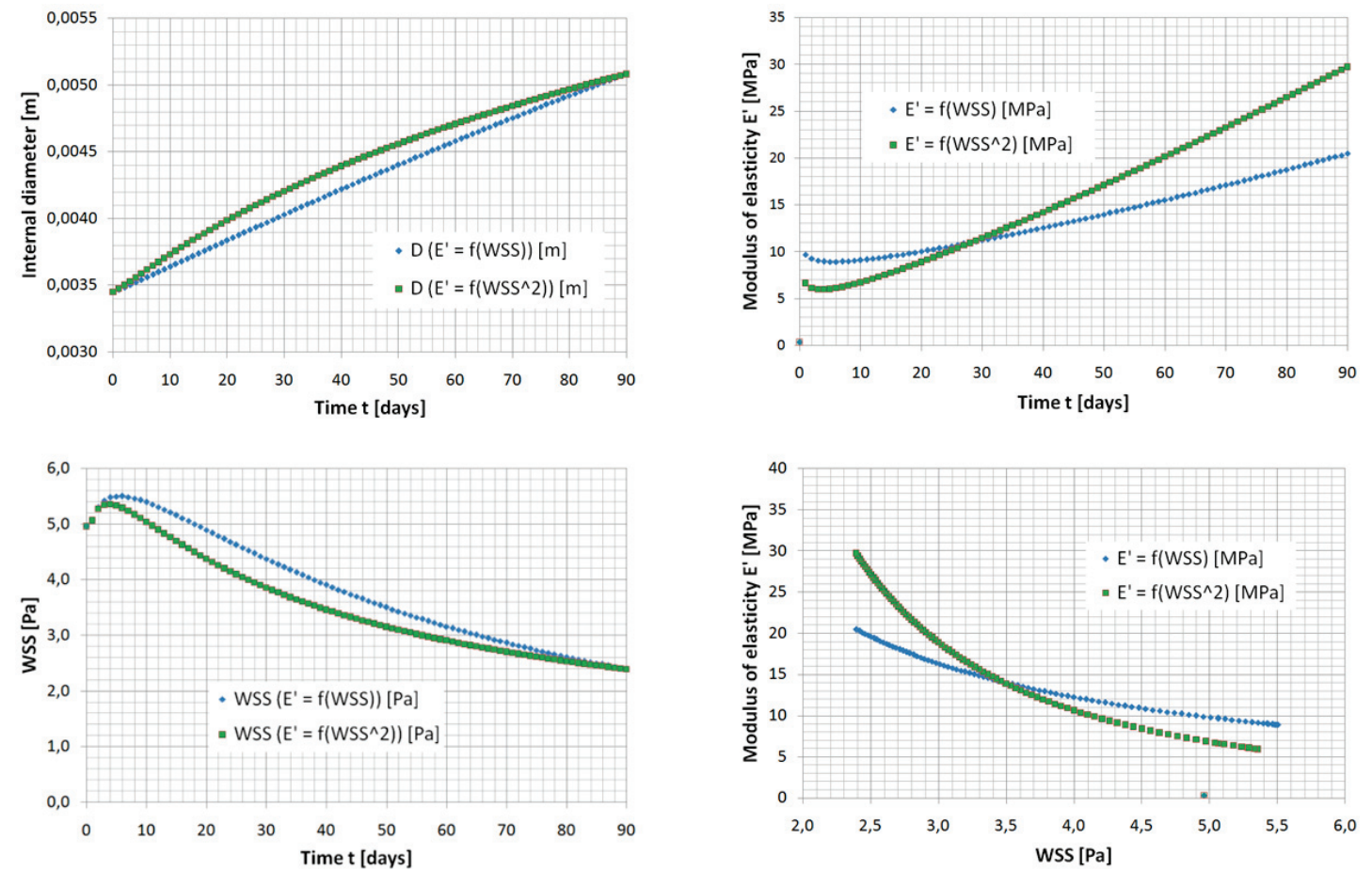

Fig. 9. Changes in the internal diameter, modulus of elasticity and averaged WSS during 90 days of modelled biological maturation process of AVF P1 obtained with constant parameters $\mathrm{A}=49 \cdot 106 \mathrm{~Pa} 2$ and $\mathrm{B}=170 \cdot 106 \mathrm{~Pa} 3$
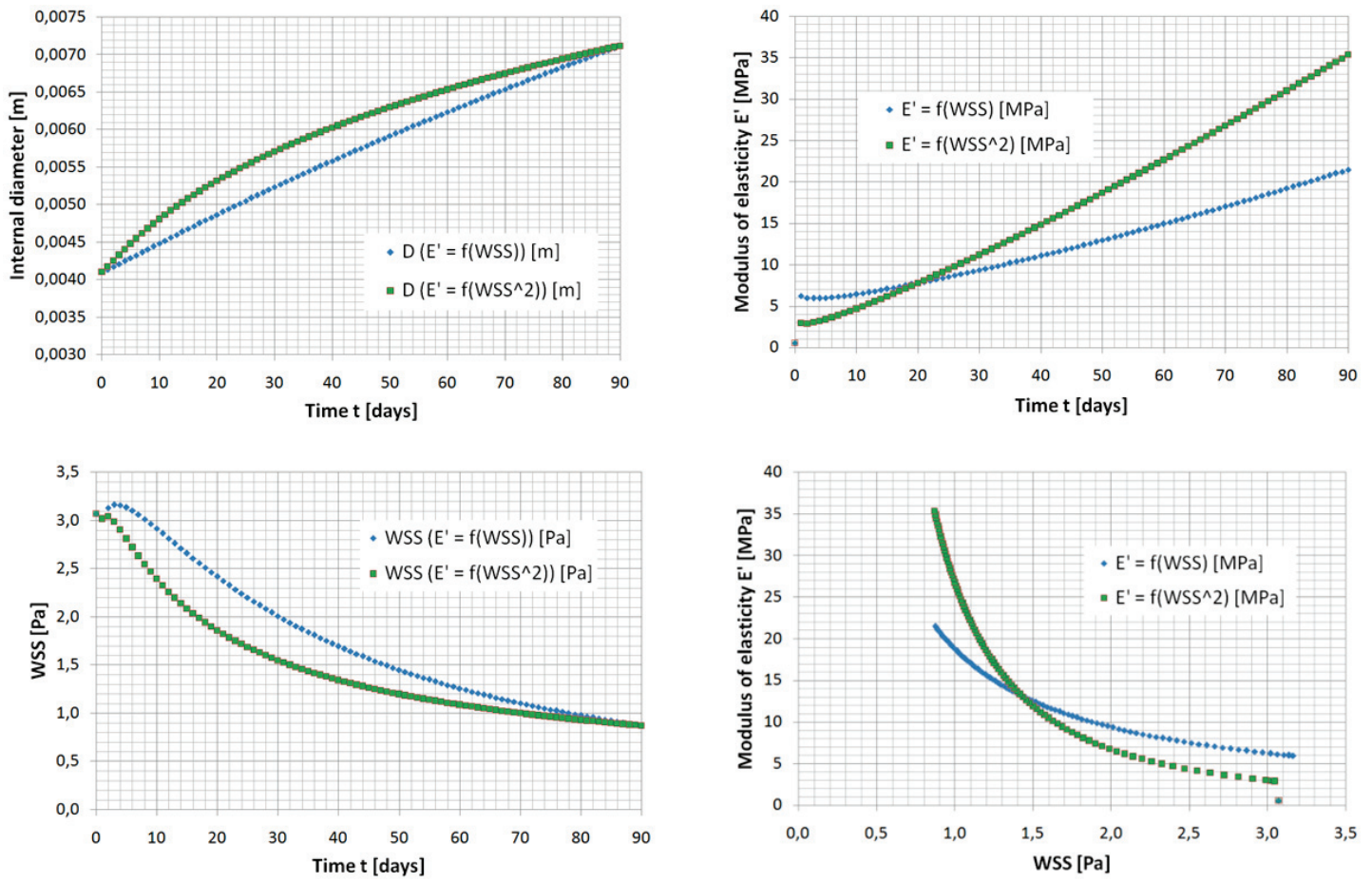

Fig. 10. Changes in the internal diameter, modulus of elasticity and averaged WSS during 90 days

of modelled biological maturation process of AVF $\mathrm{P} 2$ obtained with constant parameters $\mathrm{A}=18.8 \cdot 106 \mathrm{~Pa} 2$ and $\mathrm{B}=26.8 \cdot 106 \mathrm{~Pa} 3$

The analysis allows one to create a chart showing maturation as time functions connecting all data extracted from the curried out simulations of both stages (Fig. 12). In Figure 12, the second stage of maturation is presented for the modelling, in which modulus of elasticity is assumed to be a function of $\mathrm{WSS}^{2}$. The method, described by formulas (2)-(8) and taking into account the increase of the blood flow $Q$ according to Fig. 3, enables one to predict changes in the monitored parameters taking place in the time longer than 90 days. 

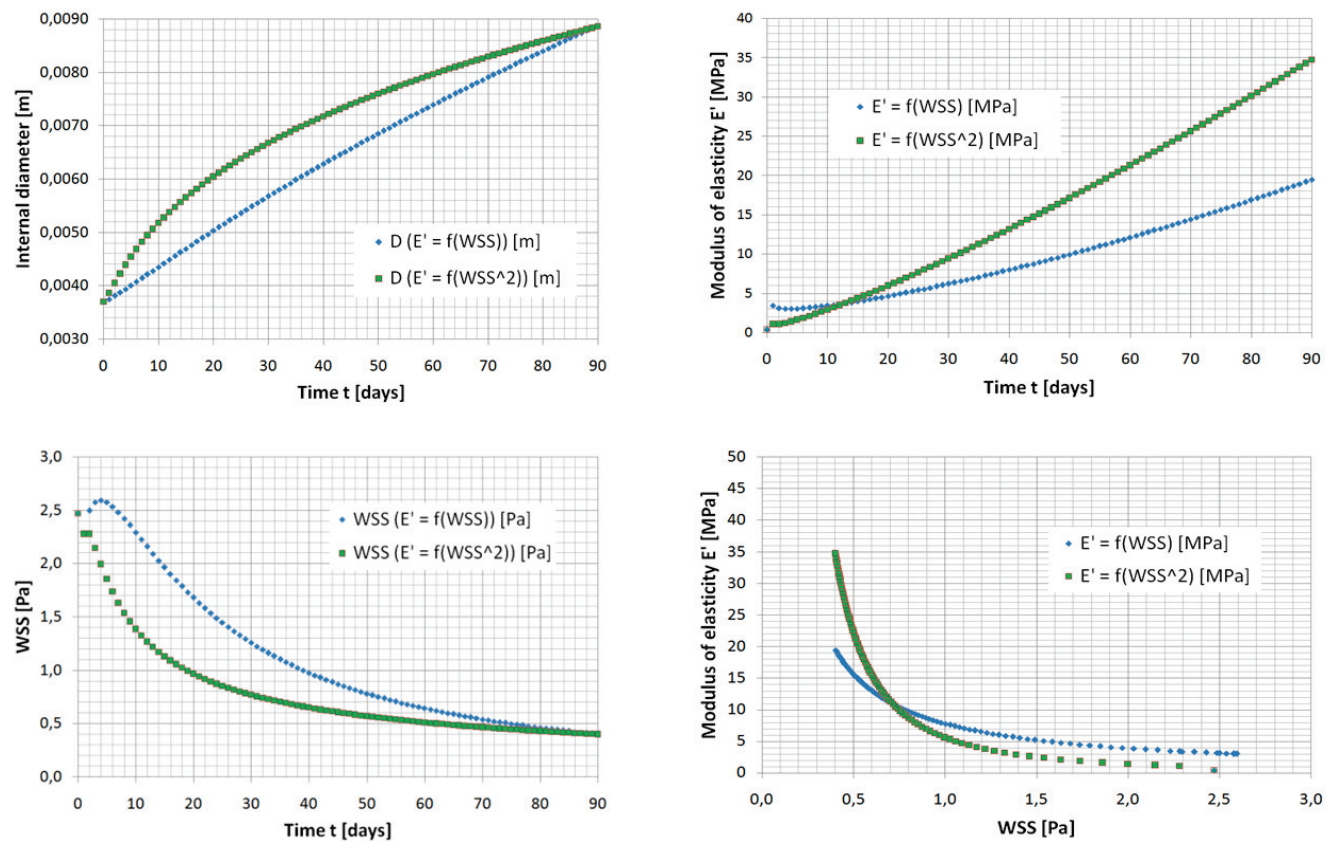

Fig. 11. Changes in the internal diameter, modulus of elasticity and averaged WSS during 90 days of modelled biological maturation process of AVF P3 obtained with constant parameters $\mathrm{A}=7.8 \cdot 106 \mathrm{~Pa} 2$ and $\mathrm{B}=5.57 \cdot 106 \mathrm{~Pa} 3$

Table 2. Comparison of pre- and postoperative diameter of radial artery and cephalic vein to data collected by other researchers [mm]

\begin{tabular}{|c|c|c|c|c|c|c|}
\hline \multirow{2}{*}{ Blood vessel } & \multirow{2}{*}{ Preoperatively } & \multicolumn{5}{|c|}{ Postoperatively } \\
\hline & & 1 day & 7-10 days & 40 days & 90-100 days & 365 days \\
\hline Radial artery & $\begin{array}{c}2.415 \\
(2.401-2.845) \\
{[9]} \\
2.7 \pm 0.6 \\
{[5]}\end{array}$ & $\begin{array}{c}4.0 \pm 0.8 \\
{[5]} \\
2.4 \pm 0.4 \\
{[11]}\end{array}$ & $\begin{array}{c}3.275 \\
(2.410-4.417) \\
{[9]} \\
3.7 \pm 0.7 \\
{[11]}\end{array}$ & $\begin{array}{c}4.7 \pm 1.0 \\
{[5]} \\
4.1 \pm 0.8 \\
{[11]}\end{array}$ & $\begin{array}{c}3.34^{*} \\
\text { (here P1) } \\
6.0^{*} \\
\text { (here P2) } \\
7.12^{*} \\
\text { (here P3) } \\
4.4 \pm 0.8 \\
{[11]} \\
4.2^{*} \pm 0.8 \\
{[29]} \\
3.2^{* *} \pm 0.6 \\
{[29]} \\
\end{array}$ & NF \\
\hline Cephalic vein & $\begin{array}{c}3.0^{* *} \\
\text { (here P1-P3) } \\
3.2^{*} \pm 0.7 \\
{[29]} \\
2.6^{* *} \pm 0.7 \\
{[29]} \\
3.0^{* * *} \pm 0.9 \\
{[29]} \\
2.6 \pm 0.8 \\
{[5]} \\
2.37 *(2.00-3.66) \\
{[9]}\end{array}$ & $\begin{array}{l}3.47-\underline{3.48}^{* * *} \\
\quad \text { (here } \mathrm{P} 1) \\
\begin{array}{l}4.14-\underline{4.17}^{* * *} \\
\quad(\text { here } \mathrm{P} 2)\end{array} \\
3.75-\underline{3.87}^{* * *} \\
\quad \text { (here } \mathrm{P} 3)\end{array}$ & $\begin{array}{c}3.58-3.64 * * * \\
(\text { here } \mathrm{P} 1) \\
4.37-\underline{4.62} 2^{* * *} \\
(\text { here } \mathrm{P} 2) \\
4.15-\underline{4.82 * * *} \\
(\text { here } \mathrm{P} 3) \\
4.43 *(3.04-6.14) \\
{[9]}\end{array}$ & 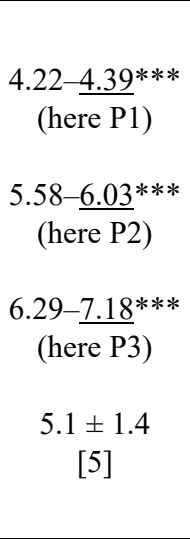 & $\begin{array}{c}5.08 * * * \\
\text { (here P1) } \\
7.12 * * * \\
(\text { here P2) } \\
\\
8.86^{* * *} \\
\text { (here P3) } \\
6.62 *(3.55-7.14) \\
{[9]} \\
5.8 \pm 1.2 \\
{[29]}\end{array}$ & $\begin{array}{c}\left.\frac{6.83}{(\text { here }}-8.51 \text { P } 1\right) \\
\frac{9.71-12.80^{* * *}}{(\text { here } \mathrm{P} 2)} \\
\frac{12.91-18.40^{* * *}}{\text { (here P3) }}\end{array}$ \\
\hline
\end{tabular}

[5] - 22 patients; [9] - 6 patients; [11] - 28 patients; [29] - 46 patients (60 patients for preoperative data);

$*$ - near elbow, $* *$ - near wrist, $* * *$ - in the middle of forearm, NF - not found

There is a lack of data regarding the place of measurements in [5] and [9].

Here - the results obtained for 1, 7, 40 and 365 days in modelling of the biological stage of maturation with use a function $E^{\prime}=f\left(\mathrm{WSS}^{2}\right)$ are underlined; the values given for 90 days were obtained from measurements on angio-CT scans of mature AVFs. 


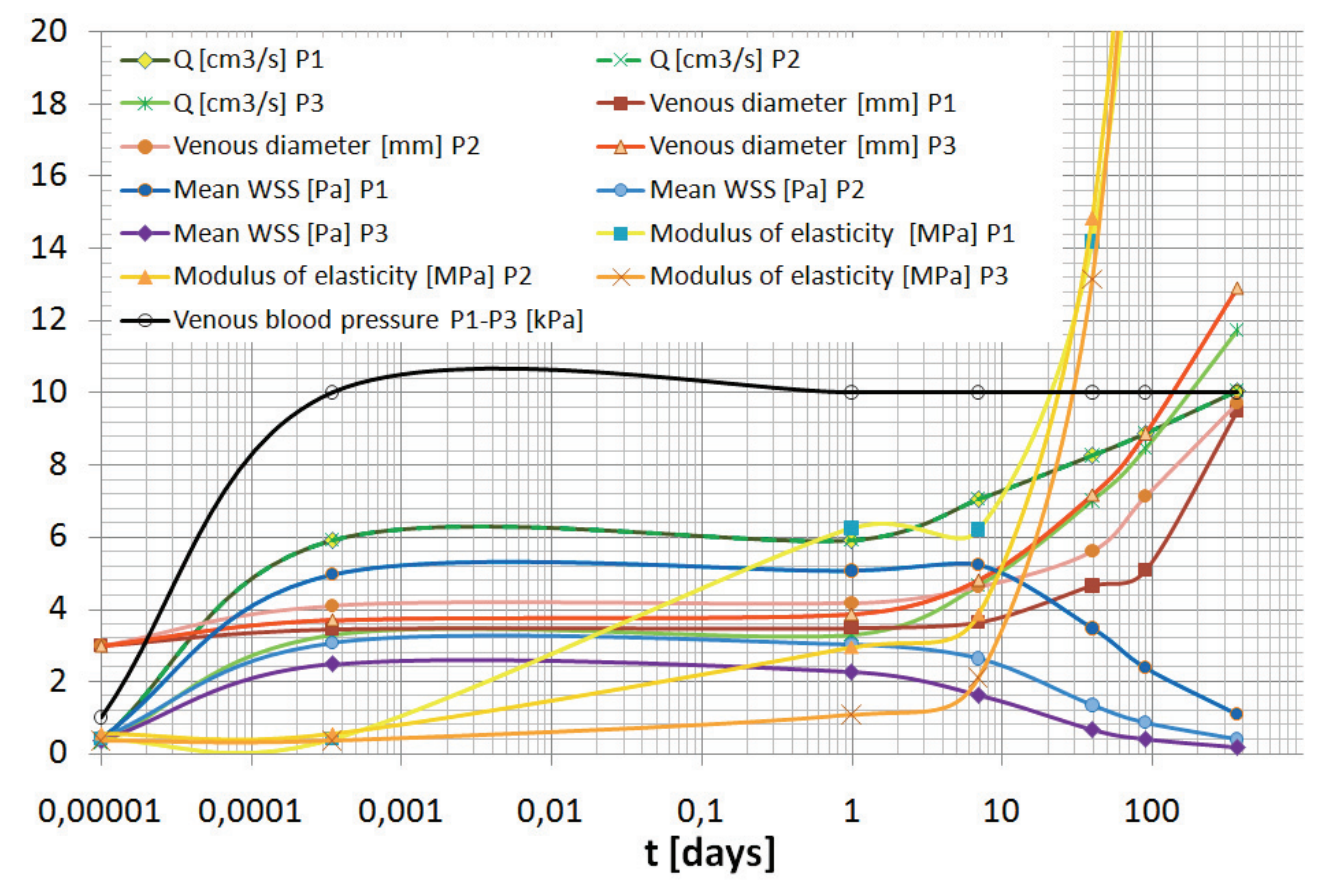

Fig. 12. Time functions of AVF maturation process

\section{Discussion}

Maturation of AVF was modelled and considered to be a complex mechano-biological process divided into two stages. The change in time-averaged flow conditions in the time-scale much longer than one particular cardiac cycle was taken into account. Considering conclusions formed during previous studies [13], this approach seems to be appropriate and allows one to save computational time.

To simulate the first stage of maturation, FSI numerical simulations were performed to model venous extension as a response for mechanical factor related to the arterial pressure exerted on the internal wall of the vein. The pressure at the outlet of each AVF was assumed to be rising from the typical venous value to $10 \mathrm{kPa}(75.0 \mathrm{mmHg})$, which is higher than the value of $5 \mathrm{kPa}(37.5 \mathrm{mmHg})$, calculated as a mean of systolic/diastolic equal to $6.67 / 3.33 \mathrm{kPa}(50 / 25 \mathrm{mmHg})$ venous pressure mentioned by Dixon [10]. However, for $5 \mathrm{kPa}$, the obtained arterial pressure calculated for the arterial inlets after $30 \mathrm{~s}$ of simulation time achieved too low values equal to $7.7 \mathrm{kPa}(57.7 \mathrm{mmHg}), 6.7 \mathrm{kPa}$ $(50.2 \mathrm{mmHg})$, and $6.0 \mathrm{kPa}(45.0 \mathrm{mmHg})$, respectively for P1-P3. The use of $10 \mathrm{kPa}$ enabled us to obtain higher pressure at inlet cross-sections equal to $14.4 \mathrm{kPa}$ (Fig. 8) and $11.4 \mathrm{kPa}$ for $Q=5.92 \mathrm{~cm}^{3} / \mathrm{s}(355 \mathrm{ml} / \mathrm{min})$, respectively for AVFs $\mathrm{P} 1$ and $\mathrm{P} 2$, and $11.2 \mathrm{kPa}$ for $Q=3.28 \mathrm{~cm}^{3} / \mathrm{s}(197 \mathrm{ml} / \mathrm{min})$ for the shunt $\mathrm{P} 3$. It means that the averaged blood pressure drop between the artery and vein varies in the range of $1.2-4.4 \mathrm{kPa}$ $(9-33 \mathrm{mmHg})$, which is not as large as in experimental observations done in 6 AVFs described by Corpataux et al. [9]. The authors obtained mean pressure $16.2 \mathrm{kPa}$ vs. $4.9 \mathrm{kPa}(121.7 \mathrm{mmHg}$ vs. $36.8 \mathrm{mmHg}$ ) calculated as $0.5 \times$ (systolic + diastolic) for the radial artery respectively the vein. Nevertheless, Corpataux et al. [9] did the measurements $2 \mathrm{~cm}$ away from the anastomosis and in the area of highly disturbed blood flow, thus the measurements could be uncertain. Moreover, Corpataux et al. measured the pressure drop with catheter, thus the measures were done with use of the invasive method influencing on the measurements. The time-averaged pressure drop, measured by Browne et al. [4] in the idealized end-to-side AVF model for steady-state conditions in numerical blood flow simulation for flow rate equal to $6.67 \mathrm{~cm}^{3} / \mathrm{s}$ (400 ml/min), $8.33 \mathrm{~cm}^{3} / \mathrm{s}(500 \mathrm{ml} / \mathrm{min}), 10.00 \mathrm{~cm}^{3} / \mathrm{s}$ $(600 \mathrm{ml} / \mathrm{min})$, and $13.33 \mathrm{~cm}^{3} / \mathrm{s}(800 \mathrm{ml} / \mathrm{min})$, achieved $0.27 \mathrm{kPa}(2 \mathrm{mmHg}), 0.40 \mathrm{kPa}(3 \mathrm{mmHg}), 0.54 \mathrm{kPa}$ $(4.0 \mathrm{mmHg})$, and $0.80 \mathrm{kPa}(6 \mathrm{mmHg})$, respectively. The same authors obtained very good correlation of their numerical investigations with simultaneously obtained experimental data. In the in vitro study and FSI simulation for an patient-specific elastic model of the mature AVF, presented in [14], relatively low values of the mean pressure drop were obtained, which achieved $0.30 \mathrm{kPa}(2.2 \mathrm{mmHg}), 0.54 \mathrm{kPa}$ $(4.0 \mathrm{mmHg})$, and $0.82 \mathrm{kPa}(6.1 \mathrm{mmHg})$, respectively 
for the flow rates $3.33 \mathrm{~cm}^{3} / \mathrm{s}(200 \mathrm{ml} / \mathrm{min}), 5.00 \mathrm{~cm}^{3} / \mathrm{s}$ (300 $\mathrm{ml} / \mathrm{min})$, and $6.67 \mathrm{~cm}^{3} / \mathrm{s}(400 \mathrm{ml} / \mathrm{min})$. Higher value of the pressure drop equal to $2.4 \mathrm{kPa}$ (18 $\mathrm{mmHg}$ ) for blood flow rate $6.75 \mathrm{~cm}^{3} / \mathrm{s}(405 \mathrm{ml} / \mathrm{min})$ was obtained by Botti et al. [2] in the patient-specific rigid model of the AVF and steady flow, for which good correlation between numerical simulation and in vitro measurements was achieved. Thus, the pressure drop in AVFs is dependent not only on the value of the blood flow rate but also on the type of the AVF and patient-specific geometry of the shunt. This is obvious from the point of view of fluid dynamics, since any sudden change in velocity value or direction, which can be enhanced by the shape of the channel, generates vortices and leads to energy dissipation associated with pressure loss. However, the drop should not to be high, since the blood pressure in the venous arm of the AVF is responsible for its extension.

During the modelling of the first step of maturation mesh displacement is in the range of $1-2 \mathrm{~mm}$ for AVFs P2 and P3, since these models are fixed and stabilized in a few places. Not-supported venous arm of model P1 moved around $10 \mathrm{~mm}$ in space, which would not be possible in the human forearm, since the vessel is stabilized by surrounding tissue. However, similar values of the internal diameter equal to $3.45 \mathrm{~mm}$, $4.10 \mathrm{~mm}$, and $3.70 \mathrm{~mm}$ were achieved in the middle of forearm of AVFs P1-P3, respectively. It means that the mean venous internal diameter increased by $15-37 \%$ during the first $30 \mathrm{~s}$ after AVF creation.

Despite the vein enlargement and the fact that WSS is inversely proportional to the third power of the blood vessel radius (Eq. (3)), the mean WSS increased in each segment of all investigated AVFs (Figs. 6 and 7). It is due to the rapid change of the high resistance arterial blood flow into low resistance and fast increase of the blood flow rate. In all radial arteries mean WSS, represented here by AAWSS, did not exceed physiological arterial range reaching 1-6 $\mathrm{Pa}$ in the last timestep ( $30 \mathrm{~s})$. On the other hand, AAWSS in veins quickly achieved non-typical venous values reaching $2.5-5 \mathrm{~Pa}$ and even higher values in anastomoses up to $20.3 \mathrm{~Pa}$ (with local extreme values of WSS close to $25 \mathrm{~Pa}$ ). This sudden increase in mean or local WSS may induce biological response of the endothelium and can lead to stenosis formation and early failure of AVF maturation.

The second biological stage of maturation was simplified to 2-dimensional task and was modelled with the assumption of constant blood pressure, which is consistent with measurements done in human arteriovenous AVFs by Corpataux et al. [9]. Similar sta- bilization of pressure was observed by $\mathrm{Lu}$ et al. [17] in rat models but it should be underlined that the use animals for such investigations is controversial due to different blood flow conditions than human ones. The use of Lamé theory and relation between $E^{\prime}$ and $\mathrm{WSS}^{2}$ allowed one to keep the relation $g>0.1 \mathrm{R}$ for the whole time of 90 days for all patients. Considering a constant value of the venous thickness made it possible to take into account hypertrophic character of the modelled process, which is associated with a tissue growth and increase of its volume and mass [9], [17], [24], [25].

The proposed method of modelling of maturation process assumes the relation between modulus of elasticity of venous wall and WSS. Wall shear stress is associated with the magnitude of blood flow rate and estimated with the formula (Eq. (3)), which is appropriate for Hagen-Poiseuille flow. Obviously, this is a simplification, since the blood flow in vein can be strongly disturbed, however, this formula was used for estimation of WSS also by others [9], [12], [30]. This method enabled us to assess which pairs blood flow rate/venous diameter allow one to obtain physiological level of venous WSS (see: Supplementary materials S6, green fields). It shows that probably most of AVFs are assessed to be mature too early, since taking into consideration only the venous diameter and blood flow rate without estimation of wall shear can result in occurrence of too high WSS values.

In the modelling of the biological stage of maturation, the estimated WSS represents time-average AAWSS, which stabilizes and comes back to the typical venous level (Figs. 9-11). This approach is consistent with observations in vivo described in [9]. On the contrary, Ene-Iordache et al. observed increase in both mean WSS and max WSS during 100 days of remodelling in the radial artery of the arteriovenous shunt [11]. This observation was a base of an algorithm written for simulation of vascular adaptation proposed by the ARCH group and described in [18] and [19]. Therefore, much more patients should be investigated in different time-points of maturation with the use of newly developed ultrasound measurements methods, which are precise but safe for patients [8]. Then, CFD tools should be employed to assess whether the mean WSS comes back to the baseline values or not.

For the method in which the relation of elastic modulus and $\mathrm{WSS}^{2}$ was used, the obtained diameters are coincident with venous size measured by others in 7-, 10- and 40-day AVFs (Table 2). Figure 12 depicts all functions which were used or obtained in the study in one diagram. The graph shows the increase in ve- 
nous diameter and blood flow rate respectively to the changes of WSS, which rapidly rises at the beginning of maturation ( $30 \mathrm{~s})$. WSS is almost constant for next 7 days, and falls down reaching typical venous level for 3-month AVFs P2 and P3. WSS in the vein of the shunt P1 still remains too high for this time and achieves the value equal to around $1 \mathrm{~Pa}$ after 1 year. Thus, some AVFs are probably assessed to be mature too early, when mean WSS is still at high level. This factor can increase the risk of early failure.

\section{Conclusions}

Maturation of the AVF is a complex process, in which mechanical factors such as blood flow rate, blood pressure, and WSS affect the blood vessels used for the shunt creation and force vascular adaptation to new flow conditions. In this study, the process was divided into two stages modelled separately. The obtained results are in conformity with the data reported by other researchers, however, one should remember that time averaged parameters were a base of the presented algorithms and the way of modelling should be validated on large group of patients with newly created AVFs, which would be monitored in time during maturation process. This could indicate in which range the constant parameter B is appropriate for a particular type of the AVF.

Our intention was to develop a model as simple as possible, which would represent very complicated phenomena on macroscale and provide results comparable with in vivo large-group measurements found in works of other researchers. The use of the simplified wall representation enabled us to model maturation in an acceptable time of computations, which would be much longer if a more developed model of the structure was employed. Despite the simplification adopted in this way, the obtained results indicate that in longterm consideration of changes, such an approach, somewhat averaging the course of phenomena in time, enabled us to obtain satisfactory results.

For the last 50 years, predicting of AVF maturation success or failure have been a reason of conducting of many studies and development of a few engineering tools, which could help doctors in making decisions. However, vascular adaptation after anastomosis creation is still not completely understood. This study shows that probably majority of AVFs can be assessed to be mature too early, when the adequate blood flow rate is achieved but mean WSS still remains at the non-physiological level.
Therefore, numerical simulations of the blood flow through the AVF, allowing one to estimate WSS level, could support decision making process before first hemodialysis.

Supplementary materials are available on: https:// figshare.com/authors/Daniel_Jodko/816351

\section{Acknowledgements}

We thank Radosław Pietura, MD, and his co-workers from Medical University of Lublin, Poland, for the medical data used to develop virtual models of the presented AVFs. Funding: This project was financially supported by the preludium granted by the national science centre in Poland (2014/13/N/ST8/04031) and partially by the fund of young scientists at the Lodz University of Technology.

\section{References}

[1] Arora D., Behr M., Pasquali M., Tensor-Based Measure for Estimating Blood Damage, Artif. Organs, 2004, 28 (11), 1002-1015.

[2] Botti L., Canneyt K.V., Kaminsky R., Claessens T., Planken R.N., Verdonck P., Remuzzi A., Antiga L., Numerical Evaluation and Experimental Validation of Pressure Drops Across a Patient-Specific Model of Vascular Access for Hemodialysis, Cardiovasc. Eng. Technol., 2013, 4 (4), 485-499.

[3] Brescia M.J., Cimino J.E., Appel K., Hurwich B.J., Chronic Hemodialysis Using Venipuncture and a Surgically Created Arteriovenous Fistula, N. Engl. J. Med., 1966, 275(20), 1089-1092.

[4] Browne L.D., Walsh M.T., GRIFFIN P., Experimental and Numerical Analysis of the Bulk Flow Parameters Within an Arteriovenous Fistula, Cardiovasc. Eng. Technol., 2015, 6 (4), 450-462.

[5] Caroli A., Manini S., Antiga L., Passera K., Ene-IORdache B., Rota S., RemuZzi G., Bode A., LeERMAKers J., VAN de Vosse F.N., VANHOlder R., Malovrh M., TORdOIR J., Remuzzi A., Validation of a Patient-Specific Hemodynamic Computational Model for Surgical Planning of Vascular Access in Hemodialysis Patients, Kidney Int., 2013, 84 (6), $1237-1245$

[6] Chatzizisis Y.S., Coscun A.U., Jonas M., Edelman E., Role of Endothelial Shear Stress in the Natural History of Coronary Atherosclerosis and Vascular Remodeling, J. Am. Coll. Cardiol., IEEE T. Bio.-Med. Eng., 2007, 49 (25), 2379-2393.

[7] ChiU J.-J., ChiEn S., Effects of Disturbed Flow on Vascular Endothelium: Pathophysiological Basis and Clinical Perspectives, Physiol. Rev., 2011, 91 (1), 327-387.

[8] Colley E., Carroll J., Thomas S., Varcoe R.L., Simmons A., BARBER T., A Methodology for Non-Invasive 3-D Surveillance of Arteriovenous Fistulae Using Freehand Ultrasound, 2018, 65 (8), 1885-1891.

[9] Corpataux J.-M., Haesler E., Silacci P., Ris H.B., Hayoz D., Low-Pressure Environment and Remodelling of the Forearm Vein in Brescia-Cimino Haemodialysis Access, Nephrol. Dial. Transplant., 2002, 17 (6), 1057-1062.

[10] DiXon B.S., Why Don't Fistulas Mature?, Kidney Int., 2006, $70(8), 1413-1422$. 
[11] Ene-Iordache B., Mosconi L., Antiga L., Bruno S., Anghileri A., Remuzzi G., Remuzzi A., Radial Artery Remodeling in Response to Shear Stress Increase Within Arteriovenous Fistula for Hemodialysis Access, Endothelium, 2003, 10 (2), 95-102.

[12] FitTs M.K., Pike D.B., ANDERson K., ShiU Y.T., Hemodynamic Shear Stress and Endothelial Dysfunction in Hemodialysis Access, Open Urol. Nephrol. J., 2014, 7 (Suppl. 1 M5), 33-44.

[13] Jodko D., OBidowski D., REorowicz P., JóźwiK K., Blood Flows in the End-to-End Arteriovenous Fistulas: Unsteady and Steady State Numerical Investigations of Three Patient-Specific Cases, Biocybern. Biomed. Eng., 2017, 37 (3), 528-539.

[14] Jodko D., Palczyński T., Reorowicz P., Miazga K., OBIDOWsKi D., JóźwIK K., Determination of a Pressure Drop in the Arteriovenous Fistula with Fluid Structure Interaction Simulations and In Vitro Methods, Proc. of the ASME International Mechanical Engineering Congress and Exposition, IMECE 2017, Tampa, USA, DOI: 10.1115/IMECE2017-70402.

[15] Konner K., Nonnast-Daniel B., Ritz E., The Arteriovenous Fistula, J. Am. Soc. Nephrol., 2003, 14 (6), 1669-1680.

[16] Lillie M.A., Shadwick R.E., Gosline J.M., Mechanical Anisotropy of Inflated Elastic Tissue From the Pig Aorta, J. Biomech., 2010, 43 (11), 2070-2078.

[17] Lu X., Zhao J.B., WANG G.R., Gregersen H., Kassab G.S., Remodeling of the Zero-Stress State of Femoral Arteries in Response to Flow Overload, Am. J. Physiol. Heart. Circ. Physiol., 2001, 280 (4), 1547-1559.

[18] Manini S., Antiga L., Botti L., Remuzzi A., pyNS: An Open-Source Framework for OD Haemodynamic Modelling, Ann. Biomed. Eng., 2015, 43 (6), 1461-1473.

[19] Manini S., Passera K., Huberts W., Botti L., Antiga L., Remuzzi A., Computational Model for Simulation of Vascular Adaptation Following Vascular Access Surgery in Haemodialysis Patients, Comput. Methods Biomech. Biomed. Engin., 2014, 17 (12), 1358-1367.

[20] MENTER F.R., Two-Equation Eddy-Viscosity Turbulence Models for Engineering Applications, AIAA J., 1994, 32 (8), 1598-1605.
[21] Morbiducci U., Ponzini R., Nobili M., Massai D., MonteVeCChi F.M., Bluestein D., RedAelli A., Blood Damage Safety of Prosthetic Heart Valves. Shear-Induced Platelet Activation and Local Flow Dynamics: A Fluid-Structure Interaction Approach, J. Biomech., 2009, 42 (12), 1952-1960.

[22] NitTa K., Masakan I., Hanafusa N., Taniguchi M., HaSEgawa T. et al., Annual dialysis data report 2017, JSDT Renal Data Registry, Ren. Replace Ther., 2019, 5 (1), 1-44.

[23] OChSNer A.JR., Colp R.JR., BurCh G.E., Normal Blood Pressure in the Superficial Venous System of Man at Rest in the Supine Position, Circulation, 1951, 3, 674-680.

[24] Remuzzi A., Bozzetto M., Biological and Physical Factors Involved in the Maturation of Arteriovenous Fistula for Hemodialysis, Cardiovasc. Eng. Technol., 2017, 8 (3), 273-279.

[25] Remuzzi A., Bozzetto M., Brambilla P., Is Shear Stress the Key Factor for AVF Maturation?, J. Vasc. Access, 2017, 18 (Suppl. 1), 10-14.

[26] Reorowicz P., Obidowski D., KŁosiński P., Szubert W., STEFAŃCZYK L., JÓŹWIK K., Numerical Simulations of the Blood Flow in the Patient-Specific Arterial Cerebral Circle Region, J. Biomech., 2014, 47 (7), 1642-1651.

[27] Sigovan M., Rayz V., Gasper W., Alley H.F., Owens C.D., SAloner D., Vascular Remodeling in Autogenous Arterio-Venous Fistulas by MRI and CFD, Ann. Biomed. Eng., 2013, 41 (4), 657-668.

[28] Wesly R.L., Vaishnav R.N., Fuchs J.C., Petel D.J., GREENFIELD J.C.JR., Static Linear and Nonlinear Elastic Properties of Normal and Arterialized Venous Tissue in Dog and Man, Circ. Res., 1975, 37 (4), 509-520.

[29] Wong V., Ward R., Taylor J., Selvakumar S., How T.V., BAKRAN A., Factors Associated with Early Failure of Arteriovenous Fistulae for Haemodialysis Access, Eur. J. Vasc. Endovasc. Surg., 1996, 12 (2), 207-213.

[30] Zaromytidou M., Siasos G., Coskun A.U., Lucier M., ANTONIADIS A.P., PAPAFAKLIS M.I., Koskinas K.C., ANDREOU I., FELDMAN C.L., STONE P.H., Intravascular Hemodynamics and Coronary Artery Disease: New Insights and Clinical Implications, Hell. J. Cardiol., 2016, 57 (6), 389-400. 